Abstracta Iranica Abstracta Iranica

Revue bibliographique pour le domaine irano-aryen

Volume 28 | 2007

Comptes rendus des publications de 2005

\title{
Ghazāli and the Poetics of Imagination, Chapel Hill/ London, The University of North Carolina Press, 2005, 349 p.
}

Ève Feuillebois-Piérunek

\section{(2) OpenEdition}

1 Journals

Édition électronique

URL : http://journals.openedition.org/abstractairanica/13432

DOI : 10.4000/abstractairanica. 13432

ISSN : 1961-960X

Éditeur :

CNRS (UMR 7528 Mondes iraniens et indiens), Éditions de l'IFRI

\section{Édition imprimée}

Date de publication : 15 mai 2007

ISSN : 0240-8910

Référence électronique

Ėve Feuillebois-Piérunek, «Ghazālī and the Poetics of Imagination, Chapel Hill/London, The University of North Carolina Press, 2005, 349 p. », Abstracta Iranica [En ligne], Volume 28 | 2007, document 301, mis en ligne le 18 septembre 2007, consulté le 25 septembre 2020. URL : http://journals.openedition.org/ abstractairanica/13432 ; DOI : https://doi.org/10.4000/abstractairanica.13432

Ce document a été généré automatiquement le 25 septembre 2020.

Tous droits réservés 


\title{
Ghazāli and the Poetics of Imagination, Chapel Hill/London, The University of North Carolina Press, 2005, 349 p.
}

\author{
Ève Feuillebois-Piérunek
}

1 Il s'agit d'un essai sur l'écriture philosophique, dont la question clé est la relation entre la connaissance et la communication de celle-ci. L'A. assimile les formes de créativité et d'innovation employées par Ǵazāli dans la présentation de ses idées à une sorte de poétique, d'où le titre.

2 Le premier chapitre, Agonistics of the Self, présente les outils et définit les concepts employés par l'auteur. Dans le chapitre 2, Narrativity of the Self, Moosa analyse comment Ǵazālī pense le « soi », l'ego, à travers le récit d'imagination exemplaire. Le chapitre 3, Poetics of Memory and Writing aborde les différentes manières d'écrire de Ġazālī: l'écriture de mémorisation, l'écriture "du cœur ", l'écriture-thérapie. Le chapitre 4, Liminality and Exile, traite du conflit entre la Loi normative et la réalité intérieure de la Foi, qui mène à la sensation d'exil de l'homme spirituel en ce monde. Le chapitre 5, Grammar of the Self, étudie la conception, la provenance et les ambiguités de la connaissance. Le chapitre 6, Metaphysics of Belief, décrit l'attitude de Ġazālī envers la philosophie: les limites de celle-ci doivent être dépassées en liant ontologie et épistémologie avec l'aide de la grâce divine. Le chapitre 7, Dilemmas of Anathema and Heresy, montre les ambiguïtés de l'hérésiologie ghazalienne: d'un côté, il prêche la réconciliation et le pluralisme au sein de l'islam, mais d'un autre côté il préconise la violence contre certains mouvements (ismaéliens, philosophes). Dans le chapitre 8, Hermeneutics of the Self and Subjectivity, Moosa démontre que la connaissance de soi et de Dieu aide à discipliner le soi en faisant appel à sa sensibilité esthétique. Le chapitre 9 , Technologies of the Self and Self Knowledge, s'intéresse au travail sur soi et à l'acquisition de la connaissance éthique.

Euvre d'un philosophe, cet essai constitue un effort louable pour remettre au goût du jour la quintessence de la pensée d'un auteur $\mathrm{du} \mathrm{XI}^{\mathrm{e}-\mathrm{XII}}{ }^{\mathrm{e}} \mathrm{s}$., à l'aide de rapprochements parfois osés avec d'autres courants de pensée d'époque et de sensibilité très différentes. 
Mais cette «modernisation » de Ġazālī complique et obscurcit quelque peu le propos pour le spécialiste de la pensée islamique.

INDEX

Thèmes : 9. Philosophie

\section{AUTEURS}

ÈVE FEUILLEBOIS-PIÉRUNEK

Sorbonne Nouvelle - Paris III 